\title{
Writing with new hands
}

\author{
WALTER BRANDNER \\ Certified Court Expert for Handwriting, Vienna, Austria
}

\section{Theo Kelz with his motorbike}

The Austrian policeman Theo Kelz, born 1953, is an expert in recognizing explosives. His main hobby was and is riding a motorbike. In August 1994 he made a motorbike trip with his daughter from Vienna to Beijing. Shortly after his holiday he received the assignment to examine a suspicious object, which was found in front of a school.

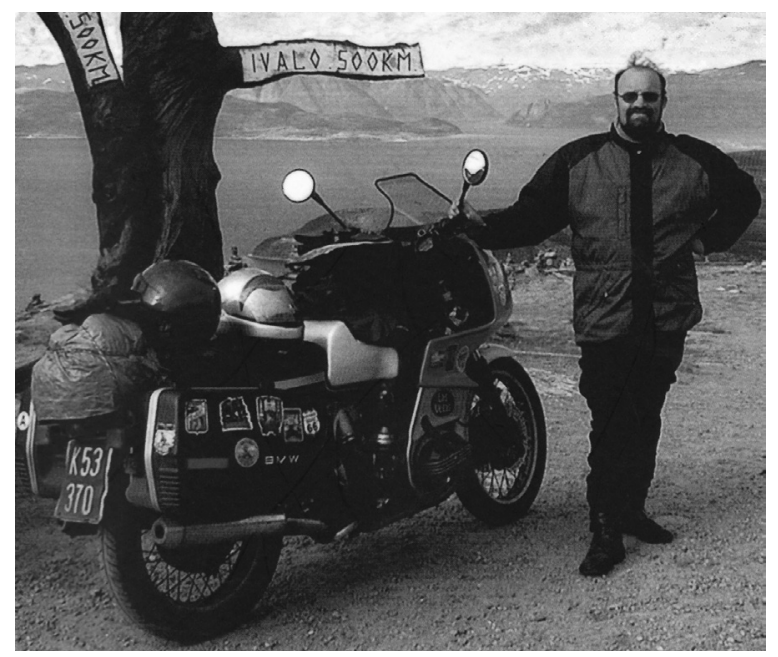




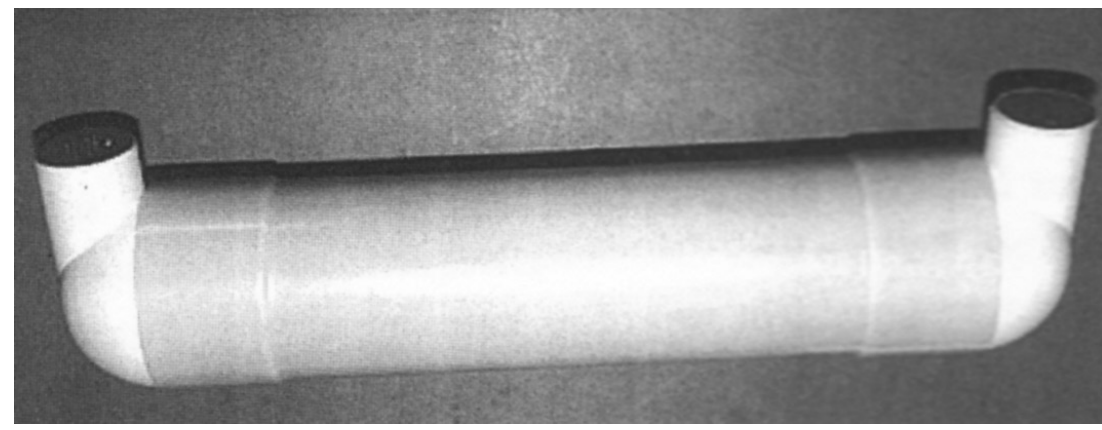

The subject was a tube. In a first step he removed a vast amount of an unknown material. When he analyzed the tube with an X-ray machine, the tube exploded and destroyed both his hands.

The responsible assassin committed in the years 1993 to 1995 various assaults on prominent persons. Some of them were seriously injured. The police succeeded to locate the assassin in 1997. The assassin lived in constant fear of an arrest and therefore always carried with him a device to kill himself. The device didn't fully work but destroyed - same as with Mr. Kelz - both his arms. The assassin was sentenced to life imprisonment. In February 2000 he hanged himself in his cell with the cord of his razor.

Now back to the subject of our topic, Mr. Theo Kelz. Mentally he coped with the loss of his hands very well and immediately wanted new, real hands. At that time, medicine was not able to transplant new hands, so at first he had to use mechanical prostheses. In 2000 he got a transplantation of real hands in a hospital in Innsbruck.

Now I will give you a brief overview of the nature and the application of his new hands. Then I will deal with the technical and medical details, which are necessary for the investigation of his writing.

Mechanical prosthesis:

The accident was in August 1994. Just two months later, Kelz received the first mechanical prosthesis. The following picture shows the initial situation of the forearms and the prostheses: 


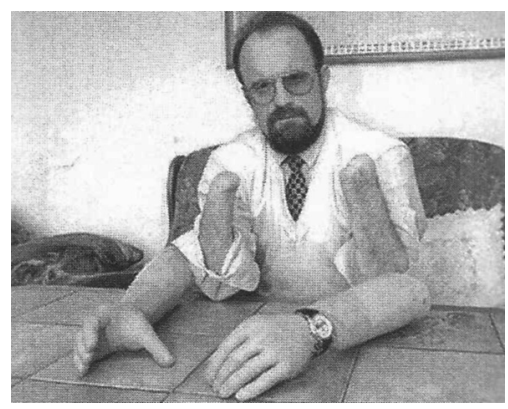

Only 10 months after his accident he returned to his job and worked full time at the police station.

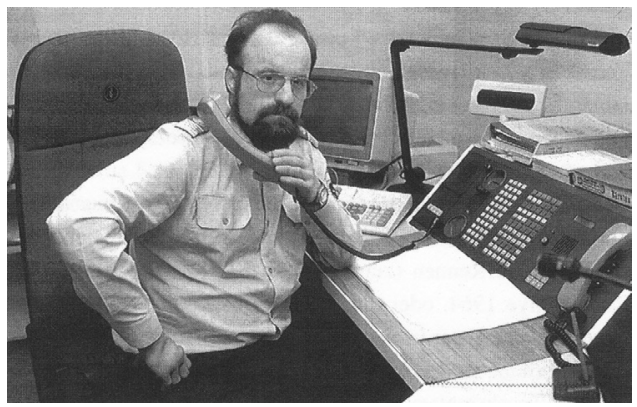

He was able to make phone calls with his prosthesis, to operate the computer, to write and drink coffee and much more.

Kelz wanted to continue his hobby of motorbike riding. He succeeded to obtain a new license in 1997 and made a first motorbike trip to Norway.

New hands:

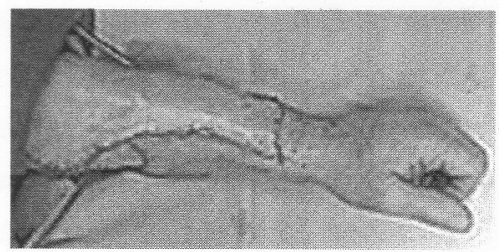

Fertige Hand links.

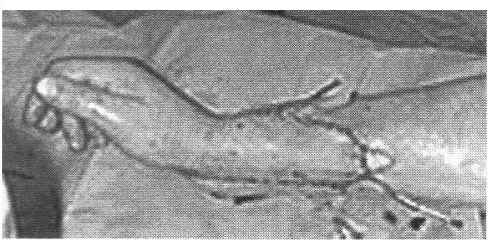

Fertige Hand rechts. 
In March 2000 in a 19-hour operation, new hands were transplanted. In December 2000, that is only 9 months later, he resumed his work at the police station, again full time.

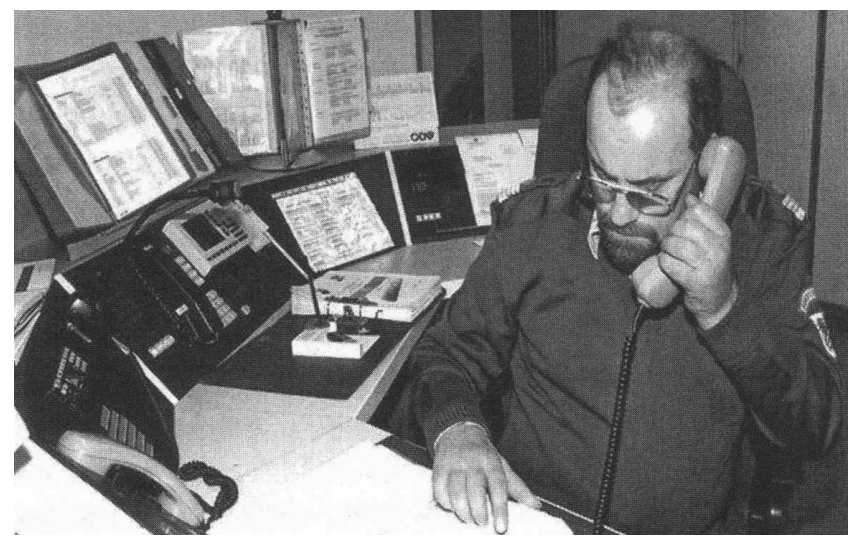

Also with his new hands he applied for and received a driving license and rode with his motorbike to the North Cape in 2002 and undertook a world tour in 2006.

The central theme of my brief presentation is the change of the handwriting.

The handwriting prior to the accident:

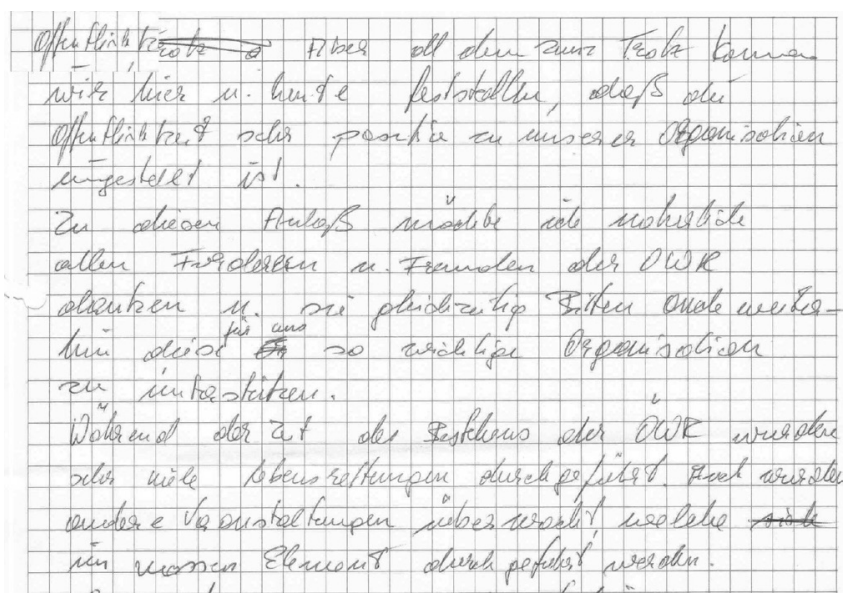

Nowa Kodyfikacja Prawa Karnego 44, 2017

(C) for this edition by CNS 
This manuscript dates from 1986. The size of the letters is average; the central zone is distinct in size and relatively stable. The upper lengths are tall, the lower lengths rather small. There is a uniform pressure; there are rare special print accents. The script is based on the given grid, the guideline is variable. The writing shows a good picture of movement, some speed, usually quickly and with some tension. The connective form shows predominantly garlands and occasional soft angles. The writing is rather narrow, the distance between the words is rather large.

Now the handwriting of Mr. Kelz with his prosthesis (1997):
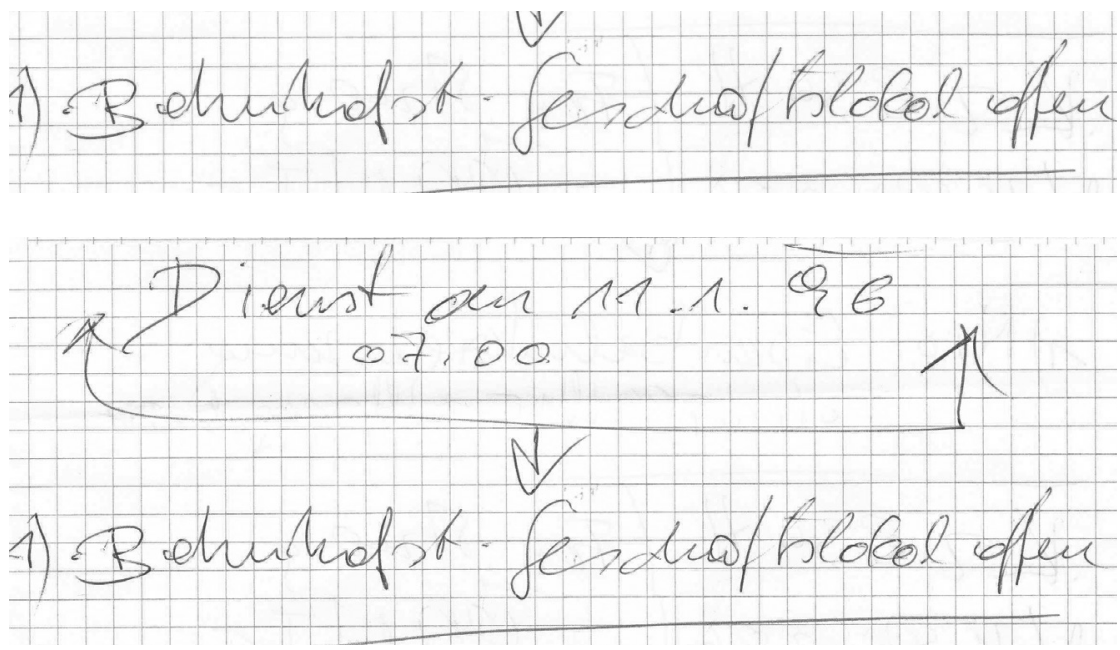

For a better understanding of writing with a mechanical prosthesis, it is necessary to outline the technical restrictions.

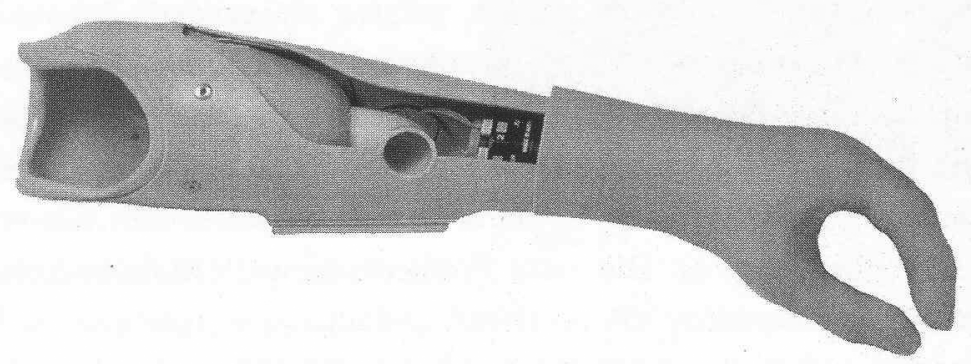


The prosthesis was a rigid element, which was placed on the forearm and provided with a mechanism. Based on an electric motor the fingers could be opened and closed, no more. The fingers could not be moved individually, the wrist was fixed and not movable. A change in the position of the hand could only be made with a rotation of the forearm. The prosthesis was steered over electrical impulses of the forearm muscles.

One of Kelz's main challenges was to control the pressure that he applied with the prosthesis. You can imagine the very big pile of broken glasses, be needed to acquire this knowledge.

A major problem was that Kelz knew and saw that he had a pen in his hand, but he could not feel it. When he wrote, he could not feel the pressure of the pen on the paper. He explained to me that it was very important for him to watch what he wrote. Three years after the accident, no one would suspect that his handwritings were written with a fixed mechanical prosthesis.

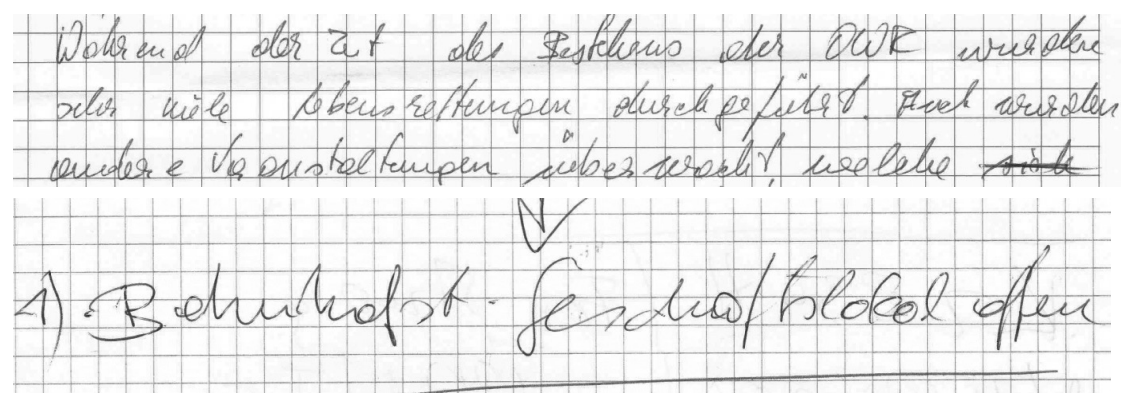

A comparison: with the prior written and with prosthesis.

The comparison of the text, written with the prosthesis, with the text before his accident shows an increase, especially its expansion. It is also a bit softer and rounder, besides restless and irregular. This is also interesting for a psychological point of view.

Handwriting with new hands

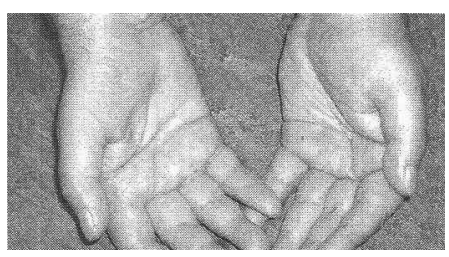




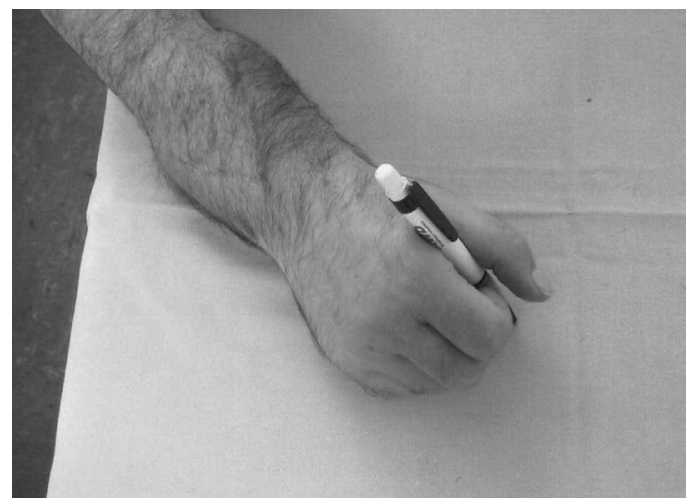

With the new hands, Mr. Kelz had a completely different situation how to write. The bones, tendons and blood vessels were connected after the operation, but the nerves had to grow back again. Another problem was that the brain had almost completely forgotten the existence of the hands. It required not only physical therapy but special mental exercises, to teach the brain to feel and move the hand.

This has been written two years after the operation:

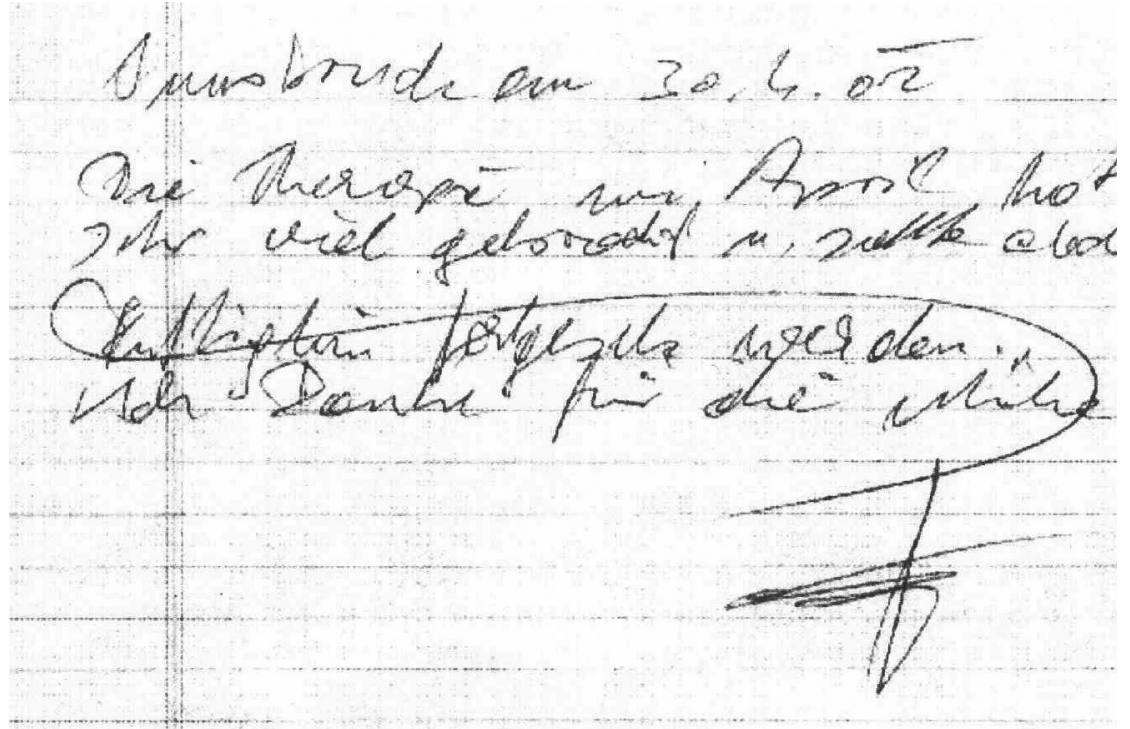


This is an image of a dedication (2012) in a book he published.

\section{THEO KELZ}

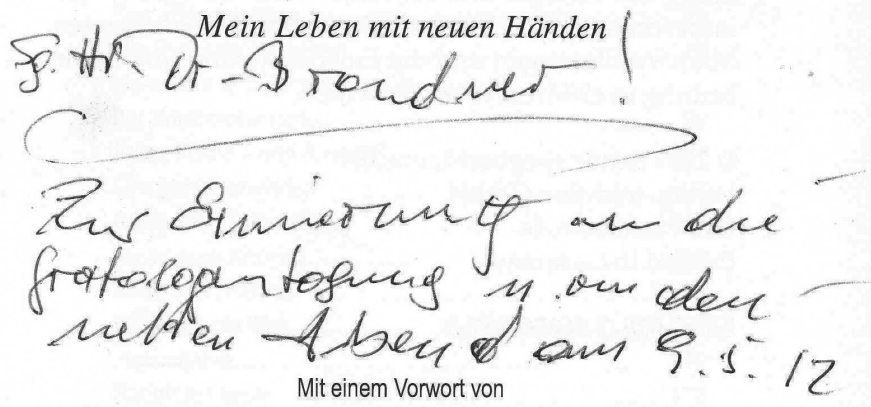

Univ. Prof. Dr. Raimund Margreiter

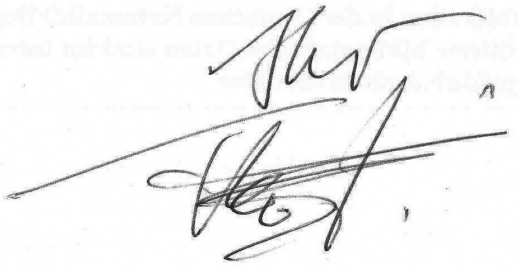

For the assessment of this writing, you have to understand a physical restriction. Since it was not possible to extend all tendons and muscles of the forearm, Mr. Kelz cannot bend his wrist downward. This leads to a restriction in his movements while writing. With the prosthesis, the biggest problem was to control the strength of the hand. Contrary, with the transplanted hands, his hand was initially very weak, and it was very difficult to hold a pen at all.

This dedication in his book shows a powerful writing and signature (2012)

I will now compare the writing of the three periods:

Before the accident

with the prosthesis

with new hands

The handwriting before the accident is moving, hurried and restless, even in the picture of letters and capable of movement. 


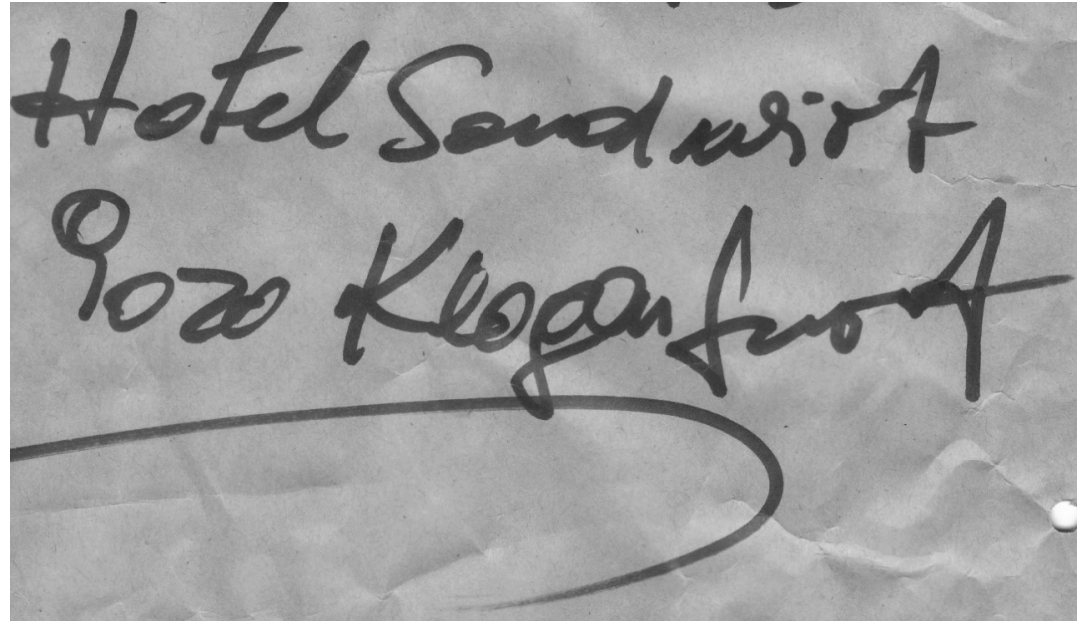

The handwriting of the prosthesis is clearly expansive in size, the width has increased. It is better in the movement, yet round and soft. The handwriting with new hands varies, depending on the writing conditions.

An anecdote: Before the transplantation the doctors told him that he could play the piano again with the new hands. Mr. Kelz commented, „I am delighted about this, because I could not play the piano before."

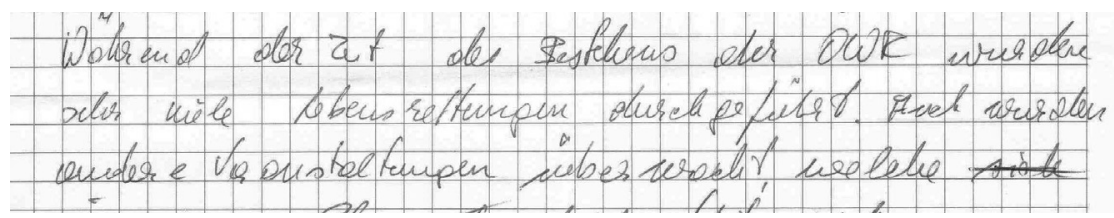

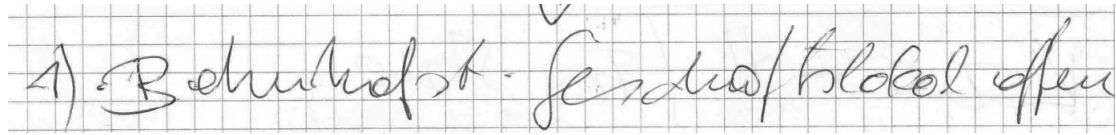

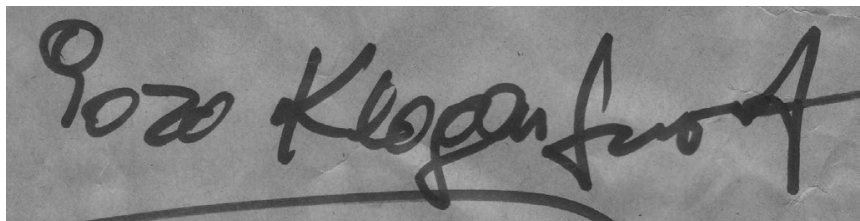

Nowa Kodyfikacja Prawa Karnego 44, 2017

(C) for this edition by CNS 


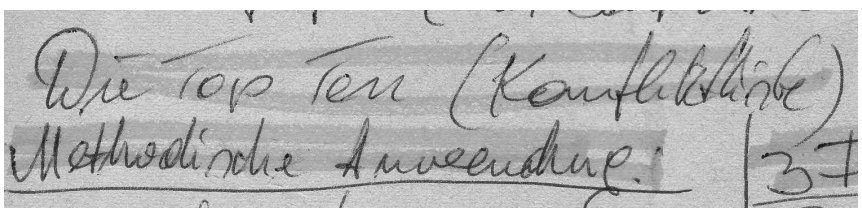

The great interest in the varied use of his new hands now led to the fact that Kelz has actually started playing the piano and now already can play simple compositions. These achievements of Mr. Kelz are the result of his the mental strength, his motivation and his dedication, which I truly admire.

Finally, I will show you a forensic comparison of the letters: "D", "W", and "g" in the original size.

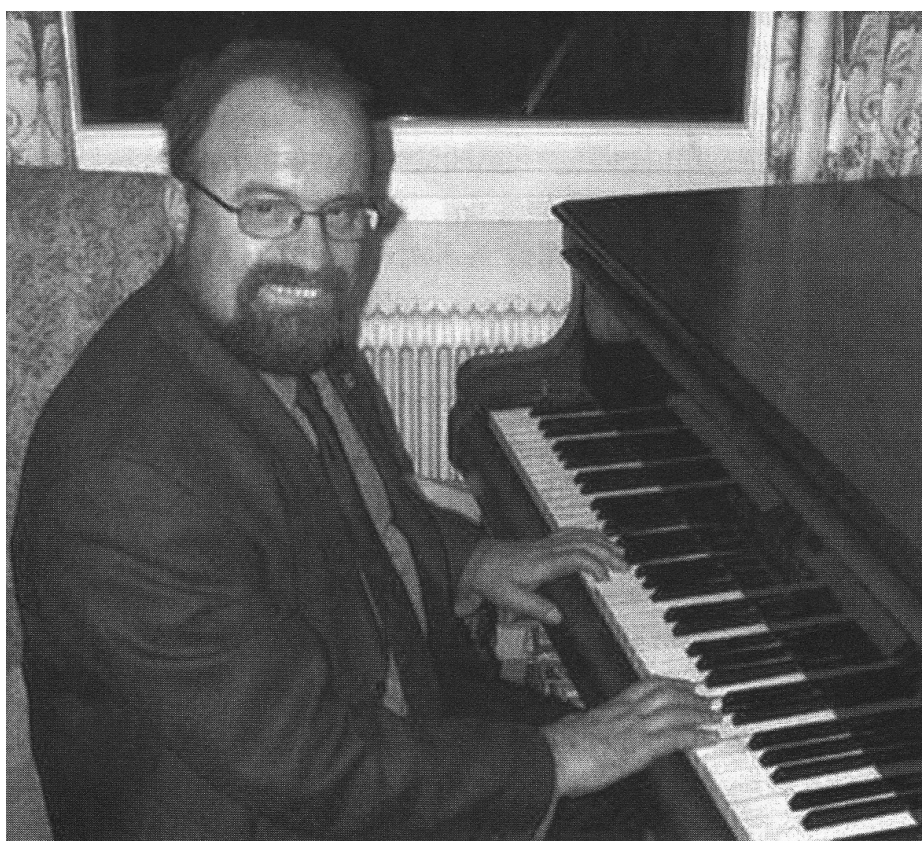

The similarities in the details prove that the writing is controlled by the brain. This leads to the conclusion that also under very difficult situations, a forensic comparison of handwritings is possible. Yet it is necessary to know all circumstances, the technical and physical details, to understand some differences, including a change in the personality. 


before the accident

\section{References}

The manuscripts and supplementary information's have been provided with the right of publication by Mr. Theo Kelz.

Some images and informations comes from the book Theo Kelz - My life with new hands, written by Siegbert Lattacher, tredition Publishing Ltd., ISBN 978-3-86850357-9, 2009, and the website of Mr. Kelz www. Theo-kelz.at.

\section{Summary}

To analyse and compare the handwriting of a person under different circumstances - with origin hands, with a mechanical prosthesis and with new transplanted hands - it is necessary to have some information about the physical conditions. The handwriting of Theo Kelz proves that the writing is controlled by the brain. This leads to the conclusion that also under very difficult situations a forensic comparison of handwritings is possible.

Keywords: handwriting with prosthesis, handwriting with transplanted hands. 